\title{
Space charge build-up in XLPE-cable with temperature gradient
}

\author{
Holbøll, Joachim; Henriksen, Mogens; Hjerrild, Jesper
}

Published in:

Proceeding of Annual Report Conference on Electrical Insulation and Dielectric Phenomena

Link to article, DOI:

10.1109/CEIDP.2000.885251

Publication date:

2000

Document Version

Publisher's PDF, also known as Version of record

Link back to DTU Orbit

Citation (APA):

Holbøll, J., Henriksen, M., \& Hjerrild, J. (2000). Space charge build-up in XLPE-cable with temperature gradient. In Proceeding of Annual Report Conference on Electrical Insulation and Dielectric Phenomena (Vol. 1, pp. 157160). https://doi.org/10.1109/CEIDP.2000.885251

\section{General rights}

Copyright and moral rights for the publications made accessible in the public portal are retained by the authors and/or other copyright owners and it is a condition of accessing publications that users recognise and abide by the legal requirements associated with these rights.

- Users may download and print one copy of any publication from the public portal for the purpose of private study or research.

- You may not further distribute the material or use it for any profit-making activity or commercial gain

- You may freely distribute the URL identifying the publication in the public portal

If you believe that this document breaches copyright please contact us providing details, and we will remove access to the work immediately and investigate your claim 


\section{Space Charge Build-up in XLPE-Cable with Temperature Gradient}

\author{
Joachim T. Holbøll, Mogens Henriksen \\ Department of Electric Power Engineering \\ Technical University of Denmark \\ Elektrovej, Building 325 \\ DK-2800 Lyngby \\ DENMARK
}

\section{Introduction}

Space charge build-up in standard XLPE insulated ACcables has been studied under varying temperature and field conditions. The cables were triple-extruded with the inner semicon on a solid aluminum conductor, $5.5 \mathrm{~mm}$ XLPE-insulation and an outer semicon. The cables were stressed up to $15 \mathrm{kV} / \mathrm{mm} \mathrm{DC}$ and temperatures were applied in the $20-80^{\circ} \mathrm{C}$ range with gradients across the insulation of up to $15^{\circ} \mathrm{C}$.

In this paper, the observed charge phenomena in the bulk and at the interfaces will be related to the external conditions, in particular to the temperature gradient. The measured space charge distributions are compared to calculated values, based on available conduction models and the deviations will be discussed thoroughly.

\section{Test Set Up}

Under the tests, space charges were measured periodically by means of the laser induced pressure pulse method (LIPP). The laser beam had an energy of $450 \mathrm{~mJ}$, a pulse width of $8 \mathrm{~ns}$ and was applied directly on the outer semicon. The number of shots per test series was limited to 50 per target area, since measurements confirmed reproducible results up to this number. After more shots the surface deterioration will affect the measured pulse shape and magnitude.

The test cables were all of type 'NKT,24kV PEX-M-Al' single core without screen or sheath. The $5.5 \mathrm{~mm}$ thick XLPE insulation had an inner/outer radius of $6.65 / 12.15 \mathrm{~mm}$ between the extruded inner and outer semicon.

The aluminum conductor, cross section $150 \mathrm{~mm}^{\square}$, was heated by an induced $50 \mathrm{~Hz} \mathrm{AC}$-current up to $400 \mathrm{~A}$. The outer semiconductor was cooled by natural convection or forced air-cooling, giving a temperature gradient of $\max .15^{\circ} \mathrm{C}$ across the insulation.

From the measured surface temperature, the conductor temperature was calculated, based on a suitable thermal model, giving an accuracy of at least $1^{\circ} \mathrm{C}$.

\author{
Jesper Hjerrild \\ NKT Research \\ Priorparken 878 \\ DK-2605 Brøndby \\ DENMARK
}

Voltage was applied to the inner conductor and the outer semicon was well grounded with respect to the high frequency pulses to be measured. A coupling and amplifying unit led the pulses to an oscilloscope.

\section{Space charge build-up}

In order to get an estimate for the expected space charge density, the following model was applied.

From a macroscopic point of view, space charge build up is known [1] to depend on the inhomogeneity of the dielectric and the charge density $\rho(x)$ can be expressed as:

$$
\rho(x)=j \cdot \nabla\left(\frac{\varepsilon}{\sigma}\right)
$$

where $\boldsymbol{j}$ is the current density, $\varepsilon$ the permittivity and $\sigma$ the conductivity. In the following, the permittivity is considered to be $2.3 \cdot \varepsilon_{0}$ and independent of the temperature and, consequently, constant through the dielectric.

The bulk conductivity is assumed only to depend on the temperature, following the simple exponential model with the activation energy $E_{a}$ as the main parameter:

$$
\sigma(T)=\sigma_{0} \cdot \exp \left(-\frac{E_{a}}{k T}\right),
$$

where $\sigma_{0}$ is the pre-exponential conductivity[2] and $k$ is Boltzmann's constant.

The temperature distribution through the insulation $T(x)$ can easily be caleulated to:

$$
T(x)=\frac{T_{\text {immer }}-T_{\text {outer }}}{0.603} \ln \frac{12.15}{x}+T_{\text {outer }}[\mathrm{K}],
$$

where $T_{\text {inner }}$ and $T_{\text {outer }}$ are the temperatures of the inner and the outer semicon, respectively. $x$ is the radial position from the conductor center axis in [mm].

From (2) and (3) the current density through the insulation was calculated and included in (1).

The influence of the space charges on the field is neglected under the current density calculations. Neither 
interface phenomena, like energy considerations and charge injection at the electrodes, are included in the model.

In figs. 1 and 2 are shown the conductivity and the space charge distribution for an activation energy of 1.1 $\mathrm{eV}$.

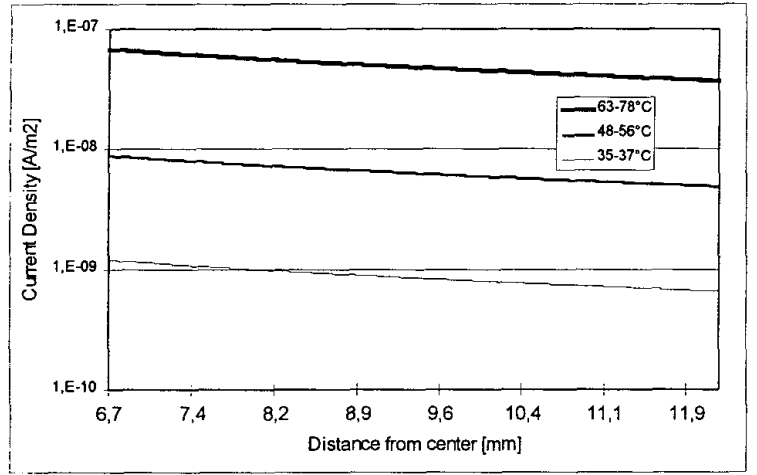

Fig. 1: Calculated current density in $24 \mathrm{kV}$-cable. The inner and outer semicon/insulation interface is at the very left and right edge of the diagram.

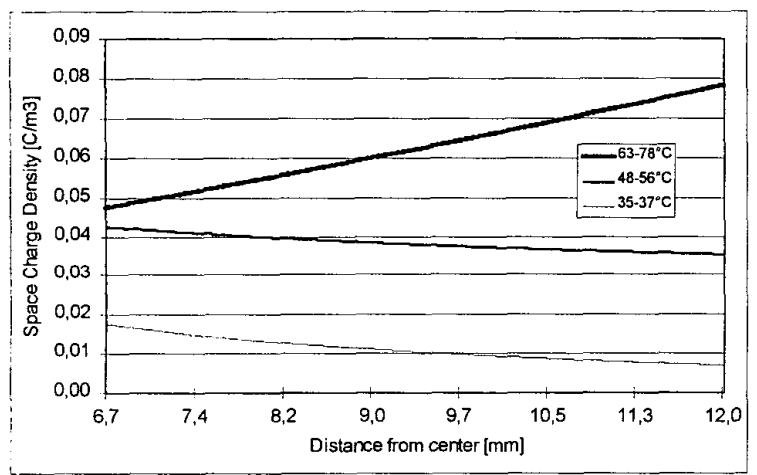

Fig. 2: Calculated space charge density in $24 \mathrm{kV}$-cable based on (1) and an activation energy $\mathrm{Ea}=1.1 \mathrm{eV}$.

The current density $\mathbf{j}$ is positive from inner to outer semicon. It clearly depends on the temperature distribution through the dielectric, as does the resulting space charge density (fig.2). For the maximum temperature gradient $63^{\circ} \mathrm{C}$ to $78^{\circ} \mathrm{C}$ most positive charges are formed at the negative outer electrode, i.e. heterocharges.

Since the actual bulk conductivity was not known, the space charge distribution was determined for different activation energies.

In the case of $63^{\circ} \mathrm{C}$ to $78^{\circ} \mathrm{C}$ temperature difference, the maximum calculated space charge density in the bulk was found to vary from 0.06 to $0.10 \mathrm{C} / \mathrm{m} 3$ for an activation energy in the range of 0.9 to $1.3 \mathrm{eV}$.

\section{Measurements}

In a number of test series on 3 cable samples of the same type but from different production series, the temporal development of the space charge distribution was measured. Either voltage or temperature was varied, according to fig. 3 .

In order to ensure a stabilized charge build up, each voltage/temperature level was kept for at least 12 hours. The maximum voltage was $+/-60 \mathrm{kV}$ corresponding to a maximum field of $+/-15 \mathrm{kV}$ at the inner semicon.

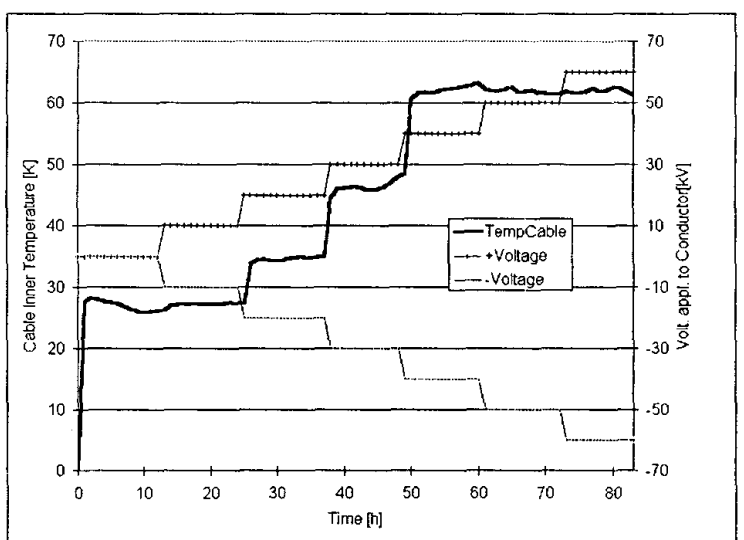

Fig. 3: Variation of Voltage or Temperature with time

All measurements shown here were done without voltage applied. Time between voltage shutdown and measurement was approximately 45 seconds.

\section{Results and Discussion}

In fig.4. can be seen the development of space charges with increasing temperature. Notice that the outer semicon now is on the left and the inner semicon is on the right. The variation of the inner electrode peak location is caused by the decreasing speed of sound with temperature.

An initial charge can be observed in the sample from former tests. This was often seen in XLPE samples, where the charge was stable for several days. Shortly after voltage application, stable heterocharges were established at the outer semicon.

In accordance to the theory, positive space charge is build up at the colder outer semicon. Surprisingly, however, the electrode adjacent space charge density does not seem to increase with increasing temperature gradient, but decreases with temperature. In particular, the charge very close to the electrode is decreasing, whereas a part closer to the center seems to be more consistent. 


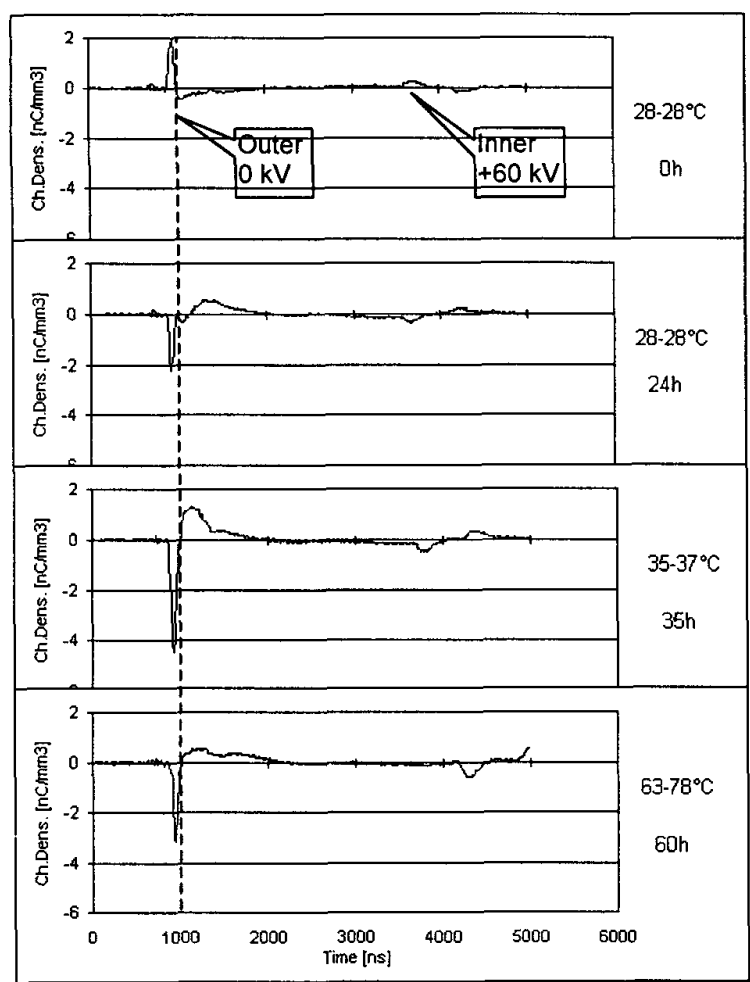

Fig.4: Space charge distribution in 24kV, XLPE cable under $+15 \mathrm{kV} / \mathrm{mm}$, DC for $60 \mathrm{~h}$ with the temperature between conductor and outer semicon increasing from $28-28$ to $63-78^{\circ} \mathrm{C}$ (outer $\rightarrow$ inner). Sample 4

The decreasing charge cannot be explained from simple electromagnetic theory. Since the decrease with temperature is limited to the area very close to the cold electrode and interface phenomena were not included in the theory, the behaviour most likely is related to the energetic conditions at the electrodes.

Only very little charge can be seen at the positive inner semicon which is clearly visible due to the charge induced from the heterocharges at the outer semicon. The peak after the inner semicon peak is the reflection from the metallic conductor.

The space charge formation and the order of magnitude of the charge density are pretty similar to those found by other authors [3], where heterocharges were found at the outer electrode for both polarities. In the present investigation, however, the charge density decreases at the highest temperature, a behaviour not found in [3]

This charge formation was found in all cable samples and, as can be seen in fig. 5, the development of the charge distribution was not dependent on the polarity of the applied voltage.

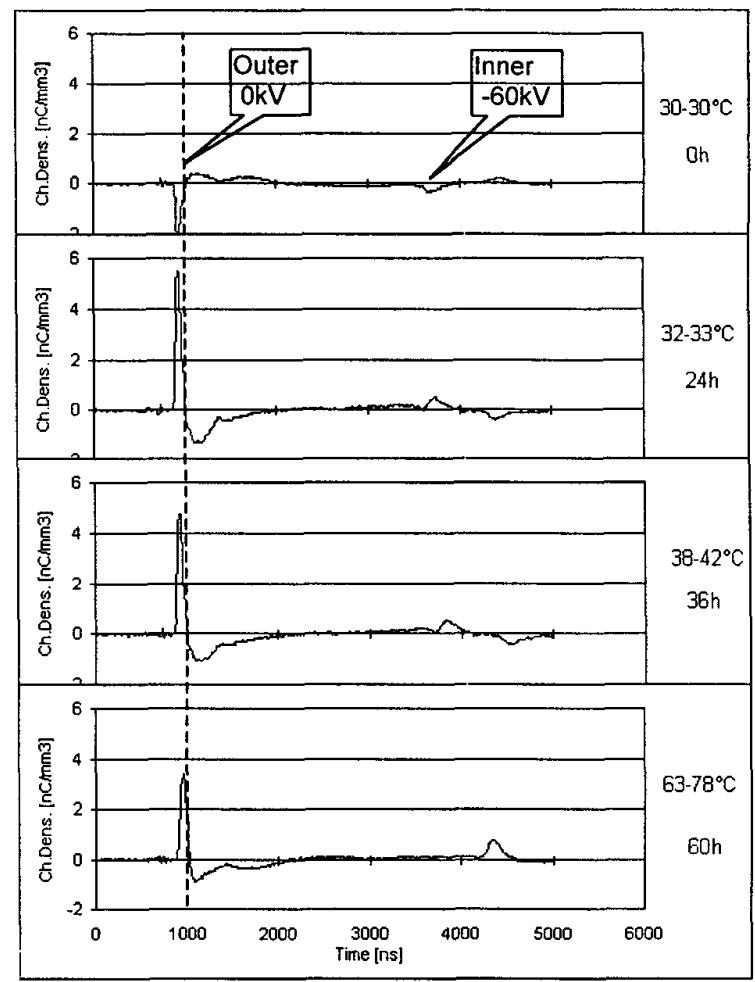

Fig.5: Space charge distribution in 24kV, XLPE cable with negative polarity: $-15 \mathrm{kV} / \mathrm{mm}, \mathrm{DC}$ for 60 hours with the temperature between conductor and outer semicon increasing from $30-30$ to $63-78^{\circ} \mathrm{C}$. Sample 3

As shown earlier, the formation of heterocharges can be dependent on heat conditioning of the sample, indicating impurities contributing to the charge formation $[4,5]$. If the heat applied in the present investigations had a conditioning effect on the cable, it could explain the decreasing charge density.

To confirm this, additional aging tests were performed with variable and constant temperatures. In fig. 6 , the space charge distribution is shown from a sample, which has been tested with heat several times. Clearly visible is a charge build-up right after voltage application similar to the final distribution, as seen in figs. 4 and 5 , at the same temperatures. This distribution was stable, as long as voltage was applied, and even after 10 hours, approximately $40 \%$ was still left in the bulk (fig.6, last diagram). Similar stable charge was found in the other samples.

Measurements of the voltage dependency of the charge formation showed a slight non-linearity. Lower charge density increase was found at higher fields, which cannot be explained by the conductivity/temperature relationship (2), but more likely indicates field dependency. 


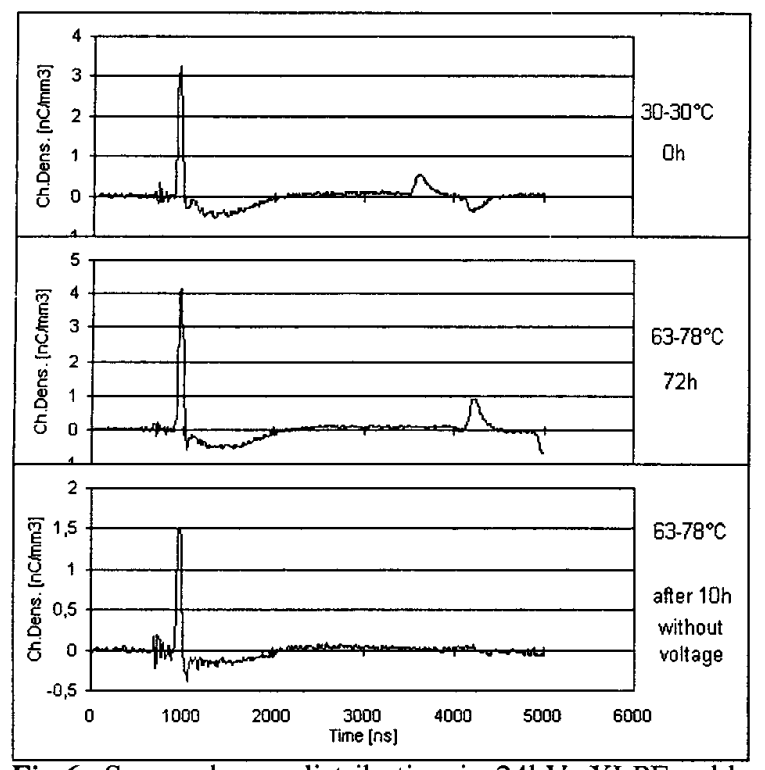

Fig.6: Space charge distribution in 24kV, XLPE cable under $-15 \mathrm{kV} / \mathrm{mm}$, DC for 60 hours with constant temperature difference of 63 to $78^{\circ} \mathrm{C}$. Test performed after several tests with variable temperature.

Since the large charge density decreasing with temperature could not be reproduced, conditioning of these cable samples most likely takes place even at surface temperatures limited to $63^{\circ} \mathrm{C}$. In $[4,5,6]$ is shown that the occurrence of heterocharges in XLPE in certain cases can be reduced considerably after conditioning at $80^{\circ} \mathrm{C}$.

The present results show charge distributions in commercial XLPE cables not fully explainable with simple electromagnetic theory, but clearly dominated by phenomena between adjacent to semicon/insulation interface. The findings have several consequences for the future work:

- The model has to be corrected by including space charges, and field-dependent conductivity.

- Conduction measurements are an essential part of the overall picture. The system will be extended to that feature.

- Attempts to distinguish between the interface and conduction related charge formation by a) Application of a higher temperature gradient and b) Use of pure and preferably conditioned test material [7].

\section{Conclusion}

Space charge measurements in heated, commercial $24 \mathrm{kV}$ XLPE-insulated cables showed, under a field of $15 \mathrm{kV} / \mathrm{mm}$, DC, a strong charge build up at the colder outer semicon.
Heterocharges were formed, the temporal development of which revealed to parts:

- a temperature dependent part which was clearly reduced at higher temperatures and

- a consistent part staying in the cable for several hours.

Shape and polarity of the measured charge distribution was in good agreement with the theory. Temperature dependency of the charge density was, however, not observed, indicating electrode/bulk effects being the main reason for the charge formation.

The investigations confirm the necessity of conduction measurements as an essential part for space charge investigations.

\section{Acknowledgements}

J.T. Holbøll expresses thanks to Dr. R. Fleming, Monash University for excellent cooperation related to this work.

Thanks to NKT-cables, Denmark for supplying the test cables.

\section{References}

[1] I.W. McAllister, G.C. Crichton, A. Pedersen, "Charge Accumulation in DC Cables: A Macroscopic Approach". IEEE International Symposium on Electrical Insulation, Pittsburgh, USA, 1994.

[2] R. Bartnikas, Engineering Dielectrics Vol. IIA, Electrical Properties of Solid Insulating Materials: Molecular Structure and Electrical Behavior." ASTM, 1983.

[3] F.N. Lim and R.J. Fleming, "The temperature dependence of space charge accumulation and DC current in XLPE power cable insulation", 1999 IEEE Annual Report - CEIDP, pp. 66-69. 1999.

[4] R.J. Fleming, M. Henriksen and J. T. Holbøll, "Space Charge Formation in XLPE - the Influence of Electrodes and Pre-conditioning". 10th Intern. Symposium on Electrets, Greece, 1999.

[5] X. Wang, D. Thu, Y. Tanaka, T. Muronaka, T. Takada, C. Shinoda, T. Hashizumi, "Space Charge in XLPE Power Cable under DC Electrical Stress and Heat Treatment", IEEE Trans Diel Elec Insul, Vol.2, pp. 467474,1995 .

[6] F.N.Lim and R.J.Fleming, "Space Charge Accumulation in Power Cable XLPE Insulation." IEEE Trans Diel Elec Insul, Vol. 6 No.3, June 1999, pp. 273-281.

[7] J.T. Holbøll, K.R. Bambery and R.J. Fleming, "Space charge and steady state current in LDPE samples containing a permittivity/conductivity gradient" CEIDP, Canada, 2000. 